\title{
UNA APROXIMACIÓN AL INTERÉS SUPERIOR DEL NIÑO Y LA PRUEBA ANTICIPADA EN LA NORMATIVA HONDUREÑA: ¿SUJETO DE DERECHOS U OBJETO DE PRUEBA?
}

\section{Enrique Flores Rodríguez*}

DOI: $\underline{\text { https://doi.org/10.5377//rd.v41i1.10491 }}$

“Nuestros niños no son peligrosos, nuestros niños están en peligro" E. Galeano.

\section{RESUMEN:}

El presente trabajo plantea el interés superior del niño como principio rector, eje y referente dentro de todos los asuntos relacionados con niñas, niños y adolescentes, implica un estudio minucioso su regulación normativa y alcance. Finalmente, este es un artículo breve para promover la base de una "Teoría del ISN" que permita estudiar los supuestos que sustentan los derechos vinculados al interés superior del niño. Ostentando su derecho a una protección especial, durante el proceso penal, por su alta condición de vulnerabilidad, hay que considerar que, durante su participación, amerita del ejercicio de garantías suficientes para acceder a la justicia en condiciones dignas que permitan el desarrollo pleno del ISN y así evitar su revictimización.

\section{PALABRAS CLAVE:}

Prueba Anticipada, Cámara Gesell, Proceso Penal, Interés superior del niño y niña, principio pro persona, sujeto de derechos y derechos del niño.

Fecha de recepción:12 de agosto de 2020 Fecha de aprobación: 30 de octubre de 2020

* Abogado y Máster en Derechos Humanos, Hondureño. Correo Electrónico : abg.kike@gmail.com 


\title{
AN APPROACH TO THE BEST INTERESTS OF THE CHILD AND THE TRIAL ADVANCE IN HONDURAN REGULATIONS: ¿SUBJECT OF RIGHTS OR OBJECT OF PROOF?
}

\author{
Enrique Flores Rodríguez** \\ DOI: https://doi.org/10.5377/lrd.v41i1.10491 \\ "Our children are not dangerous, our children are in danger" \\ E. Galeano.
}

\begin{abstract}
:
This work raises the best interests of the child as a guiding principle, axis and reference within all matters related to girls, boys and adolescents, implies a careful study of its normative regulation and scope. Finally, this is a short article to promote the basis of an "ISN Theory" that allows the study of assumptions that uphold the rights linked to the best interests of the child. Holding their right to special protection, during the criminal process, due to their high vulnerability, it must be considered that, during their participation, they deserve the exercise of sufficient guarantees to access justice in dignified conditions that allow the full development of the ISN and thus avoid its revictimization.
\end{abstract}

\section{KEYWORDS:}

Trial advance, Gesell Camera, criminal process, best interests of the boy and girl, pro person principle, subject of rights and children's rights.

Date received: August 12, 2020

Approval date: October 30, 2020

** Lawyer and Master in Human Rights, Honduras . Email: abg.kike@gmail.com 


\section{INTRODUCCIÓN}

Es necesario hacer notar, que la introducción del niño ${ }^{1}$, a la agenda internacional en materia de derechos, tiene su auge durante el siglo XX. Producto del "reconocimiento" social, legislativo y cultural, de que el niño, niña o adolescente, representa una fase primordial de la existencia humana merecedora de una especial atención (Fanlo, 2004); y por ende de especial garantía para el acceso a sus derechos.

Es el resultado de la evolución del pensamiento en materia de derechos humanos, donde subyace que toda persona, sin distinción alguna, incluyendo por supuesto a la niñez, gozan de los derechos universalmente consagrados, siendo el deber de los Estados en su posición de garante, promoverlos $\mathrm{y}$ fomentar su efectivo goce, ejercicio $\mathrm{y}$ protección. Reconociendo que, en cuestión de equidad, para acceder plenamente al ejercicio de esos derechos, debe existir una protección jurídica especial, para ciertos grupos que pueden encontrarse en una condición de vulnerabilidad. Hoy en día en Honduras, a raíz de la última reforma del año 2013, al Código de la Niñez y Adolescencia, contamos con una legislación armonizada con el espíritu de la Convención sobre los Derechos del Niño de 1989. Siendo esta última el instrumento internacional por excelencia, que rompió

\footnotetext{
1 Si bien por momentos me referiré al termino niño de forma singular, deseo aclarar, que no pretende en ningún momento desconocer el uso inclusivo del lenguaje, por el contrario, manifiesto mi postura a favor de un lenguaje jurídico inclusivo, alejado de la hetero-normatividad. Reconociendo que el uso del masculino para referirse al ejercicio de derechos, en ocasiones puede crear una confusión semántica y reproducir violencia. Sin embargo, en el contexto que se menciona en el presente artículo, se utiliza el término "niño" en referencia como lo hace la Corte Interamericana sobre Derechos Humanos. Por tanto, se entenderá para niña y niño, en su conjunto.
}

paradigmas y se convirtió en la principal fuente de derecho en materia de niñez, para la positivización de los derechos del niño.

En el ámbito internacional destacan dos precedentes que también fueron considerados hitos fundamentales en la materia. La Declaración de Ginebra de 1924 y la Declaración Universal de Derechos del niño de 1959. Pero es hasta la Convención sobre Derechos del Niño, cuando jurídicamente la concepción del sujeto cambia, ya que no solo se considera al niño y niña como un objeto de protección, sino como un sujeto de derechos en sí mismo (Zermatten, 2003). Los niños, hasta entonces, habían sido concebidos como objetos de la política social, un objeto de compasión, supeditando el ejercicio de sus derechos a su papel como "deberes impuestos a la familia uti singuli ${ }^{2}$ y a las instituciones gubernamentales" (Fanlo,2004, p.10). La Convención sobre Derechos del Niño (CDN), con la concepción del niño como sujeto de derecho, obliga un cambio de percepción y mentalidad, una construcción de la perspectiva de derechos humanos desde un lado más sensitivo, introduciendo una nueva definición jurídica, que atiende la particularidad del grupo a proteger: El interés superior del niño ${ }^{3}$.

Sin embargo, esta construcción teórica no siempre se encuentra desarraigada de una visión adulto céntrica, que implica la perpetuidad de las relaciones de poder de los

2 El niño era una obligación. El bienestar del niño se construye alrededor de lo que se cree bueno para él, pero no dentro de lo que, a él, como individuo, le corresponde por derecho.

3 Si bien en el derecho anglosajon habían existido antecedentes que referían un título similar, bajo la concepción del "bienestar del niño”; es hasta la Convención que se empieza a definir los alcances del niño, como sujetos de derecho, por encima de ser solamente objeto de protección. 
adultos sobre los niños y niñas (Ávila, 2012), que puede verse invisibilizada por las "buenas intenciones" de la visión paternalista sobre lo que "cree" puede ser beneficioso para la persona menor de edad o, mejor dicho, para las niñas, niños y adolescentes.

El interés superior del niño, además de ser un concepto garantista y proteccionista, es un concepto controversial. Es así que lo primero que tendríamos que cuestionarnos, más allá del innegable carácter obligatorio y vinculante, es ¿Quién decide sobre su aplicación?, por regla general sus representantes, maestros, abogados y jueces, quienes pueden presentar dificultades para operar de manera imparcial, aun considerando que puedan tener la mejor intención, les (nos) puede resultar muy difícil, resolver un conflicto sin mirarlo bajo los lentes de la ideología propia y la convicción personal. Sin embargo, conscientes del reto que implica un concepto que puede considerarse abstracto o subjetivo, la forma de hacerlo es "pensando única y exclusivamente en el niño, con sus necesidades, sentimientos y escala de valores distintos de los que presentan los adultos" (Ballesté, 2012). Por ello entonces, es momento de preguntarnos ¿Qué es el interés superior del niño?

\section{METODOLOGÍA}

Para el presente trabajo se utilizó la metodología de la Investigación jurídica en $\underline{\text { su modalidad de metodología práctica }}{ }^{4}$, con

4 La metodología práctica se ocupa de conocer la forma en que resuelven los jueces (o un órgano administrativo) una controversia jurídica. Se preocupa por su razonamiento, por sus criterios de argumentación, por la forma en que son capaces de interpretar las normas en el caso específico resuelto por ellos. De modo tal que se pueda construir de forma ordenada y lógica, un método que servirá para que otros jueces o doctrinarios el fin de facilitar el estudio y razonamiento con el cual en la práctica judicial se ha venido construyendo los conceptos de interés superior del niño y de prueba anticipada, su relación con el enfoque diferencial para el acceso a la justicia y el proceso penal. Ante esto, la metodología dogmática-académica de la doctrina, permite cuadrar de forma ordenada los diversos estamentos que, por sí solos en la legislación son difíciles de distinguir, sin una guía o una estructura doctrinal, para definir, clasificar e identificar los supuestos de cada figura (estándares) en el ámbito judicial ${ }^{5}$. Esta Metodología de la Investigación jurídica permitió el estudio y análisis de la legislación procesal penal, la normativa referente a niñez y la jurisprudencia vigente en Honduras, mediante el vivo intercambio entre la doctrina, la jurisprudencia y la ley. Basada en la corriente de investigación jurídico pura -desarrollada por Sánchez Zorrilla- sirven como herramientas prácticas para dilucidar dentro de una norma su contenido y estructura.

hagan lo mismo. Este razonamiento resulta atractivo no sólo para la metodología del derecho, pues, en vista de que los jueces tienen que motivar sus sentencias, mediante razonamientos congruentes del veredicto al que llegó él o ellos (cuando es colegiado) o el jurado (si el sistema los utiliza) en un caso concreto; es comprensible que esta forma de trabajar haya ocasionado que la epistemología también le preste atención. Así, Popper utiliza este razonamiento para sostener que las hipótesis científicas (o la decisión final a la que llega el jurado), no pueden ser inferidas por procedimientos inductivos, sino que únicamente pueden justificarse "por medio de otros enunciados - o deducirlos lógicamente de ellos-:

5 Para Sánchez Zorrilla (2011) existen dos preocupaciones con este método. La primera preocupación que tienen es saber qué significa el texto de una norma; es decir, exponernos qué casos resuelve esa norma (o normas), o, en segundo lugar, decirnos cuál es la respuesta adecuada a un problema planteado. En ambos asuntos las investigaciones doctrinales cumplen el rol de manuales 18. Por lo cual, la doctrina actual, casi unánimemente, sostiene que las construcciones dogmáticas tienen que cumplir un fin práctico. 


\section{EL INTERÉS SUPERIOR DEL NIÑO DESDE LA CDN Y EL DERECHO INTERNACIONAL}

El concepto del interés superior del niño se encuentra regulado en el artículo 3 de la $\mathrm{CDN}$, en su párrafo primero define:

En todas las medidas concernientes a los niños que tomen las instituciones públicas o privadas de bienestar social, los tribunales, las autoridades administrativas o los órganos legislativos, una consideración primordial a que se atenderá será el interés superior del niño.

Lo primero que definiremos es el ámbito de aplicación, podemos denotar fácilmente que al referir "en todas las medidas concernientes a los niños", su aplicación es amplia y no restrictiva, absolutamente en todos los asuntos donde intervengan niños ${ }^{6}$, tendrá que considerarse el interés superior.

Continuando con la definición del interés superior del niño (ISN), dentro del ámbito de su competencia define quienes tienen las facultades para considerar el principiocomoeje rector "las instituciones públicas o privadas de bienestar social, los tribunales, las autoridades administrativas o los órganos legislativos". Estos actores no pueden desprenderse de la obligación que tienen de garantizar el efectivo ejercicio del ISN, sin embargo, no se puede negar que, debido a los contextos nacionales suscitados en América Latina, el mayor peso termina cayendo sobre el sistema de justicia,

6 Para los efectos del presente documento y en base a lo establecido en el art. 1 de la Convención, se entiende por niño todo ser humano menor de dieciocho años de edad. sin que los demás lleguen a reflexionar acerca de cómo mejorar y perfeccionar, la atención y las prácticas cotidianas a favor de la niñez, que garanticen un acceso efectivo a todos los derechos (Bruñol, 1999).

Este desprendimiento por parte de gran parte de la población, no es solamente desconocimiento de la legislación, sino también falta de sensibilización. Todas las instituciones públicas, privadas, órganos administrativos y demás que trabajen el tema de niñez, en los distintos sectores: salud, educación, justicia, etc. deben considerar el ISN en la toma de sus decisiones diarias, para garantizar prácticas profesionales, desprovistas de arbitrariedad. Tampoco podemos negar la falta de sensibilización de los actores del sistema de justicia quienes tratan a la niñez todavía bajo el concepto de "menor infractor", es decir, solamente como responsable de la comisión de un ilícito penal, dejando de un lado la importancia de comprender las razones de vulnerabilidad que exponen a los niños y niñas, a entrar en conflicto con la ley (IBCR, 2017).

Además, como versa el mismo artículo 3 "una consideración primordialaqueseatenderá será el interés superior del niño", recayendo así el sentido hermenéutico del principio. El "Pro-niño (a)" que establece el artículo en mención, se encuentra estrechamente ligado al principio pro persona y al ejercicio del control de convencionalidad. El pro homine o pro persona alude a que toda interpretación de la normativa, en caso de conflicto, debe resolverse a favor de garantizar los derechos humanos del individuo (Pinto, 1997). Es decir que su interpretación no debe ser restrictiva, 
debido a que el fin del ISN es satisfacer las necesidades del niño y garantizar la totalidad de sus derechos.

La Corte Interamericana de Derechos Humanos en la Opinión Consultiva OC 17/02 de la Condición Jurídica y Derechos Humanos del Niño, en resolución del 28 de agosto del 2002, estableció que el objetivo de los instrumentos internacionales en cuanto a la protección de los derechos del niño es "el desarrollo armonioso de la personalidad de aquéllos y el disfrute de los derechos que le han sido reconocidos". Por ello enfatiza la Corte Interamericana que la CDN ha establecido primordialidad o prevalencia del principio del ISN, también reconociendo que existe una doble protección del niño o niña al tenor de lo que establece el art. 19 de la Convención Americana sobre Derechos Humanos.

En el caso de la Masacre de las Dos Erres vs Guatemala, de la Sentencia de 24 de noviembre del 2009, la corte resuelve que "la prevalencia del interés superior del niño debe ser entendida comola necesidad de satisfacción de todos los derechos de los niños, que obliga al Estado e irradia efectos en la interpretación de todos los demás derechos de la Convención en cuanto se refiera a menores de edad". En la misma sentencia recalca que se debe prestar "especial atención a las necesidades y a los derechos de los niños", atendiendo su particular condición de vulnerabilidad. En base a lo anterior podríamos decir que, para resolver un asunto tomando en consideración el ISN debemos hacer un examen ponderando los derechos del niño o niña, y si la resolución toma en consideración cada uno de los elementos y presupuestos de los derechos inherentes al ISN, dentro de un cuadro fáctico como quien realiza una "Teoría del ISN".

\section{EL ISN EN LA LEGISLACIÓN HONDUREÑA Y LA OBSERVACIÓN N${ }^{\circ} 4$}

\section{El Código de la Niñez y Adolescencia} en Honduras fue Reformado mediante Decreto 35-2013, del 27 de febrero de 2013 y publicado en el Diario Oficial La Gaceta el 6 de septiembre de 2013. Como parte de la reforma se implementa el nuevo modelo de justicia penal juvenil, donde se armonizó el contenido en razón de la Convención sobre Derechos del Niño y en virtud de atender la exigencia que el derecho internacional de los derechos humanos, demanda en materia especial de niñez del Estado hondureño en su posición de garante. Es así, que dentro de la normativa se encuentra el ISN regulado en dos artículos: el art. $5 \mathrm{y}$ el art. $180 \mathrm{~B}$ inciso a.

El art. $180 \mathrm{~B}-\mathrm{a}$, establece los principios rectores del sistema de justicia penal juvenil entre ellos el interés superior que se define "sin perjuicio y en concordancia con lo dispuesto en el artículo 5 de este código, el sistema estará dirigido a asegurar el pleno y efectivo ejercicio y disfrute de todos los derechos y garantías del niño (a)". Cuando el articulo refiere sin perjuicio y en concordancia, estable un criterio de interpretación sujeto a los límites y exigencias del art. 5 del mismo cuerpo legal, además de recalcar subsiguientemente que el ISN está dirigido a la plena satisfacción y acceso de los derechos y garantías de la niñez, la finalidad del sistema no es solamente el juzgamiento, es la posición del niño (a) como un sujeto vulnerable, donde se pueda aminorar 
factores de riesgo o de vulnerabilidad ${ }^{7}$ y ponderar la intervención estatal a favor del niño o niña (CIDH, 2015).

Es así que, el artículo 5 de la Codificación vigente enHonduras en materia de niñez, define el interés superior del niño y le da tres alcances como derecho, principio interpretativo y norma procedimental, lo que permite que el mismo asegure la dignificación del niño como el sujeto de derechos que es. Percibir al niño (a) desde esta concepción implica respetar los alcances que tiene el ISN, sin subestimarlos, ni infra valorar sus intereses, su capacidad de ejercicio de sus propios derechos y por ende su capacidad de acción; dejar de verlos como "seres en desarrollo" y empezar a tratarlos como "seres completos" (Liebel, 2015). La norma citada versa así:

Artículo 5. Las disposiciones de este Código se interpretarán y aplicarán siempre de manera que aseguren una eficaz protección a los derechos de los niños, niñas y su superior interés. En todas las medidas que tomen las instituciones públicas o privadas, los tribunales, las autoridades administrativas o los órganos legislativos, la consideración primordial que se entenderá será la del interés superior del niño. Se interpretarán y aplicarán, además, teniendo en cuenta los Tratados y Convenios sobre los derechos de la niñez, aprobados y ratificados por Honduras, los que prevalecen sobre el Derecho Interno. Debiéndose respetar:

7 Tomando en cuenta que según lo establecen las reglas de Brasilia para el acceso a la justicia tanto niñez como privación de libertad, son factores que aumentan la vulnerabilidad de las personas, a estas condiciones habrá que atender el enfoque diferencial del caso, donde podría incorporarse situaciones como ser género y pobreza.
1) Su condición de sujeto de derecho,

2) El derecho de los niños y niñas a ser oídos y que su opinión sea tenida en cuenta;

3) El respeto al pleno desarrollo personal de sus derechos en su medio familiar, social y cultural;

4) Su edad, grado de madurez, capacidad de discernimiento y demás condiciones personales,

5) El equilibrio entre los derechos y garantías de los niños y niñas y las exigencias del bien común; $y$,

6) Su centro de vida. Se entiende por centro de vida el lugar donde los niños y niñas han transcurrido en condiciones legítimas la mayor parte de su existencia.

Cuando exista conflicto entre los derechos e intereses de los niños y niñas frente a otros derechos e intereses igualmente legítimos, prevalecerán los primeros.

Este triple alcance del artículo 5 se encuentra íntimamente ligado al art. 3 de la $\mathrm{CDN}^{8}$, reafirmando la idea que toda aquella persona dentro de la función pública o privada que tenga que considerar medidas a tomar en relación a la niñez está obligada a valorar y sopesar el ISN bajo estos tres parámetros. Primero como derecho sustantivo brinda una garantía del ejercicio de los derechos del niño por encima de otros intereses; Segundo como principio interpretativo asegura que en caso de conflicto se deberá adoptar la decisión que satisfaga de manera más efectiva el ISN; y 8 En su Observación General no. 14 (UNCRC, 2013), el Comité de los Derechos del Niño, efectúa una interpretación jurídica del art. 3 de la CDN que es el que introduce el concepto del interés superior del niño como principio rector. Dicha interpretación define el término a) como derecho sustantivo; b) como principio jurídico interpretativo fundamental y c) como norma de procedimiento. 
Tercero como norma procedimental parte del debido proceso exige dejar patente que en la toma de decisiones concernientes a niños y niñas se ha tomado en cuenta el ISN (UNCRC, 2013).

En la observación $\mathrm{N}^{\circ} 14$ del Comité de Derechos del Niño, plantea una serie de elementos que se deben de tomar en cuenta para sopesar una decisión basada en el ISN, un examen -a mi punto de vista-, un filtro para desvincular la visión subjetiva de quien la puede interpretar, una "Teoría del ISN". Por ello si concatenamos, este instrumento internacional, con el art. 5 del Código de la Niñez y adolescencia, podremos ponderar los presupuestos que exige la consideración del interés superior del niño. Los elementos en razón de los derechos vinculados al principio rector del ISN, que deben considerar son:

1) La opinión del niño: donde su situación de vulnerabilidad, no le priva del derecho a escuchar su opinión (ar.12 CDN).

2) La identidad del niño: No es un grupo homogéneo y es necesario atenderles bajo un enfoque diferencial y especializado, sin discriminación alguna (art.20 CDN)

3) La preservación del entorno familiar: Interprentando a "familia" en un sentido amplio, donde se debe valorar las relaciones afectivas del niño o niña en su entorno (art. 5 y $9 \mathrm{CDN}$ ).

4) Cuidado, protección y seguridad del niño (a): Implica una interpretación amplia y no negativa. No se protege al niño de supuestos daños, se garantiza al niño de un bienestar físico, psíquico y moral, en razón de sus necesidades.

5) Situación de vulnerabilidad: El interés superior de un niño en una situación concreta de vulnerabilidad no será el mismo que el de todos los niños en la misma situación de vulnerabilidad. Las autoridades y los responsables de la toma de decisiones deben tener en cuenta los diferentes tipos y grados de vulnerabilidad de cada niño, ya que cada niño es único y cada situación debe evaluarse de acuerdo con su condición única (Reglas de Brasilia).

6) El derecho del niño a la salud: La salud tanto física como mental, es un derecho fundamental que debe garantizarse a los niños y niñas, en aras de su bienestar.

7) El derecho del niño a la educación: Tanto como el derecho a la salud, este derecho persiste indistinto a la condición jurídica del niño o niña, y los actores involucrados en los procesos de niñez, están obligados a valer con igual celo, el libre ejercicio del mismo. La educación del niño no es restrictiva y tiene que estar vinculada a sus aspiraciones personales y su vocación particular.

Considerando lo anterior, debemos tener en cuenta que la definición del niño de la CDN y del Código de la niñez y adolescencia de Honduras, mantiene un rango de edad entre 0 y 18 años. Por lo cual atender el interés superior del niño, requiere de un examen individual, tomando en cuenta cada uno de los derechos que persisten en esa persona, por su particularidad y especialidad. Recordar que, el verdadero ISN supera el argumento cronológico de la edad, por uno particular tomando en consideración las experiencias y expectativas del niño o niña. Lejos de la visión adulto céntrica que cargamos en nuestras espaldas, debemos hacernos acompañar de 
otros profesionales en áreas específicas, para ponderar de la mejor manera el ISN, tomando en consideración que nuestras decisiones deben sustentarse en el bienestar del niño o niña, cuyo ejercicio y acceso no está limitado y por ende estamos obligados a defenderlo. Para ello el art. 5 del CNA, brinda la potestad del control convencionalidad y el principio pro persona, en caso de conflicto entre la normativa o los intereses del niño o niña frente a otros de igual categoría.

\section{LA PRUEBA ANTICIPADA}

\section{Generalidad}

La prueba anticipada es aquella practicada antes del juicio — con intervención del juezen condiciones que permitan la contradicción, cuando fuere de temer que no podrá practicarse en el juicio oral o que algo pudiera motivar su suspensión o perdida (Elguera, 2009, p.29). Es una potestad de las partes en el proceso, la solicitud del anticipo de la prueba y la idea es preservar la prueba frente algún problema futuro que suponga su perdida. Como versa el C.P.P. se utilizará "en caso de peligro de pérdida o inutilización de cualquier medio de prueba, el órgano jurisdiccional, a petición del Ministerio Público o de cualquiera de las partes, adoptará las medidas necesarias para evitar el peligro, y en su caso, ordenar la recepción anticipada de la prueba"9. Entendiendo que está práctica anticipada no es exclusiva para testimonios o declaraciones, sino cualquier medio que pueda ser cubierto por los presupuestos de puesta en peligro, perdida o inutilización, es decir, la no disponibilidad de la misma.

9 Articulo 277 C.P.P.
El Código nos expone varios supuestos mediante los cuales, las partes pueden solicitar la práctica de una prueba mediante el anticipo jurisdiccional:

- Cuando exista peligro grave de que resulte imposible o extraordinariamente difícil su práctica en el acto del debate.

- Cuando exista riesgo grave de fallecimiento de un testigo o perito.

- Por ausencia o por cualquier otra causa, sea imposible o extraordinariamente difícil que comparezca en el acto del juicio.

- Que el testigo corra peligro de ser expuesto a presiones, mediante violencia, amenazas, ofertas o promesas de dinero u otros beneficios análogos.

- Cuando se trate de los supuestos a que se refiere el Artículo 237-A.

Amparadoen el principiode lacontradicción e igualdad de partes, el requisito indispensable que sustenta la petición del anticipo es la participación de todas partes en la misma, so pena de nulidad. Donde los "interesados que hasta el momento hayan sido identificados y que puedan comparecer, y estos tendrán derecho a asistir a la práctica anticipada de la prueba, en la forma prevista para el debate. El imputado que se encuentre detenido, será representado por su defensor, salvo si pide intervenir personalmente y no existe peligro de fuga" 10 .

Excepcionalmente el mismo artículo 277, establece dos supuestos que pueden limitar dicha garantía, primero en aquellos casos en que se desconozca quién es el imputado $\mathrm{y}$, segundo, cuando la práctica de la prueba 10 Ídem 
sea de extrema urgencia, donde el Ministerio Público podrá requerir la intervención del juez para que actúe de la manera más expedita, debiendo citar éste un defensor de oficio para que controle el acto.

\section{CÁMARA GESELL Y CONDICIONES DE VULNERABILIDAD}

\section{Conceptos}

Entendiendo que el anticipo jurisdiccional de la prueba es el medio para conocer un hecho o circunstancia en un proceso penal; la cámara Gesell es la herramienta o diligencia que ayuda a preservar la integridad de dicho medio, para protección y no revictimización de las víctimas y testigos con alto grado de vulnerabilidad.

Sin embargo, a pesar de que la cámara Gesell es la herramienta más conocida para promover la mitigación del hecho victimizante durante el proceso penal, el uso de herramientas análogas no debe restringirse. Así el código procesal penal tiene el precepto autorizante en el art. 237 B donde la participación de las personas, en el proceso, en condición de vulnerabilidad será llevada a cabo en espacio o sala con espejo unidireccional o especialmente acondicionada o en la Cámara de Gesell u otros medios análogos, con la facilitación de un profesional de la psicología. Teniendo en cuenta por regla general que, La práctica de esta diligencia se realizará con las formalidades de la prueba anticipada.

El uso del o la profesional en psicología, como versa el Protocolo para Cámara Gesell emitido por el Ministerio Público, se sustenta en los estándares internacionales de atención a víctimas, con el ideal de un modelo de atención integral. Donde el agente estresante (hecho delictivo o victimizante), puede afectar gravemente a nivel fisiológico, afectivo, cognitivo y emocional (Gonzales, Delgado, García, 2010), lo que limita o dificulta su derecho al acceso a la justicia ${ }^{11}$. Entendiendo que la prueba es la declaración que emana de la víctima o testigo; y la víctima o testigo es el sujeto de derechos.

Por tanto, loque trata de evitarlaherramienta es, primero la revictimización que en ocasiones puede provocar mayor trauma que el mismo hecho delictivo (Mantilla, 2015); y segundo, preservar la declaración con todas las garantías del contradictorio, para que la víctima no sea expuesta nuevamente al proceso penal. Para muchos autores la victimización secundaria se define como las consecuencias psicológicas, sociales, jurídicas y económicas negativas que dejan las relaciones de la víctima con el sistema jurídico penal, supone, un choque frustrante entre las legítimas expectativas de la víctima y la realidad institucional, involucrando una pérdida de comprensión a cerca del sufrimiento psicológico y físico que ha causado el hecho delictivo, dejándolas desoladas e inseguras y generando una pérdida de fe en la habilidad de la comunidad, los profesionales y las instituciones para dar respuesta a las necesidades de las mismas (Botero, Coronel, 2009).

11 Para la Dra. Mantilla “...se debe defender y promover la justicia garantizando una adecuada atención en la que el riesgo de revictimización sea minimizado durante el proceso o durante el contacto de la víctima con los servidores y operadores jurídicos...”. 
Por todo ello, la no repetición de la declaración de la víctima o testigo, cuya situación de vulnerabilidad puede verse agravada, es una forma de mitigación del daño y una pequeña parte de un proceso integral de atención. Por eso estas declaraciones deben ser siempre admitidas por el órgano jurisdiccional en todas las etapas del proceso, no siendo necesaria una nueva comparecencia o declaración de la víctima o testigo, salvo en aquellos casos en que surjan noticias de circunstancias o acontecimientos relacionados con el hecho imputado o de su autor, siempre y cuando se haya respetado las garantías del proceso $^{12}$.

\section{Condición de vulnerabilidad}

Es necesario entender que el concepto de igualdad en materia de derechos humanos tiene que ser interpretado en términos de equidad; porque el paradigma es comprender que el principio intenta se otorgue un trato igual a todas aquellas personas que se encuentran en situación o circunstancias similares. Esto conduce a la utilización de criterios de "diferenciación", es decir, el otorgar un trato diferenciado a personas que se encuentran en una situación particular, impulsado en las reglas de Brasilia como el enfoque diferencial. Por ello, el concepto de igualdad no es un término uniforme, ni absoluto y vacío, de aplicación automática, sino que requiere de un constante juicio de justeza por ser un "concepto dinámico" debido a que los hechos y fenómenos sociales no son patrones de un solo estándar (IIDH, 2011, p.21).

12 Art. 277 C.P.P.
La manera de lograrlo es mediante lo que se conoce como "acción afirmativa" (discriminación positiva), que no es otra cosa que generar mayores oportunidades a personas y colectividades cuyas dificultades para participar en igualdad de condiciones ante el sistema se ven limitadas en razón de su particularidad e individualidad, base para el enfoque especializado. Grupos de personas que son excluidas por "su condición étnica (indígenas y afrodescendientes), de género (mujeres), edad (niños, niñas y adolescentes, y adultos mayores) o por algún tipo de reto especial (discapacidad), requieren de un trato equitativo para compensar esa desventaja, de manera temporal" (IIDH et al, p.23).

\begin{tabular}{|c|c|}
\hline \multicolumn{2}{|l|}{ Definición } \\
\hline $\begin{array}{l}\text { Código Procesal Penal } \\
\text { Art. } 237 \text { A. }\end{array}$ & $\begin{array}{l}\text { Reglas de Brasilia para el } \\
\text { Acceso a la Justicia: Regla } \\
n^{\circ} 3\end{array}$ \\
\hline $\begin{array}{l}\text { Se consideran en } \\
\text { condición de vul- } \\
\text { nerabilidad aquellas } \\
\text { personas que, por razón } \\
\text { de su edad, género, } \\
\text { estado físico o mental } \\
\text { se encuentran espe- } \\
\text { cialmente expuestos a } \\
\text { la revictimiza-ción y en } \\
\text { condición de dificultad } \\
\text { para participar en los } \\
\text { actos y diligencias que } \\
\text { conlleva el proceso } \\
\text { penal... }\end{array}$ & $\begin{array}{l}\text { Se consideran en condición } \\
\text { de vul-nerabilidad aquellas } \\
\text { personas que, por razón de su } \\
\text { edad, género, estado físico o } \\
\text { mental, o por circunstancias } \\
\text { sociales, económicas, étnicas } \\
\text { y/o culturales, encuentran } \\
\text { especiales dificultades para } \\
\text { ejercitar con pleni-tud ante } \\
\text { el sistema de justicia los de- } \\
\text { rechos reconocidos por el } \\
\text { ordenamiento jurídico. }\end{array}$ \\
\hline
\end{tabular}

El art. 237 A. del C.P.P. establece algunas condiciones de vulnerabilidad, las cuales están sujetas a este enfoque diferencial y especializado, entre ellas están:

1) Personas menores de dieciocho (18) años de edad, cuando sean llamadas al proceso como testigos o víctimas de delitos contra 
la libertad e integridad física, psicológica y sexual y; hechos violentos;

2) Mujeres víctimas de violencia intrafamiliar, delitos en perjuicio de la libertad e integridad física y corporal, psicológica y sexual;

3) Personas con limitaciones mentales o sensoriales; $y$,

4) Las víctimas o testigos en los supuestos de extorsión y asociación ilícita.

Sin embargo, como versa el mismo artículo, esta descripción no debe entenderse de forma restrictiva; pudiendo comprender la pluralidad de condiciones que regulan las Reglas de Brasilia para el acceso a la justicia de grupos en condición de vulnerabilidad y El Reglamento de la Comisión Judicial de Acceso a la Justicia de la Corte Suprema de Justicia de Honduras ${ }^{13}$, como ser género (en un sentido más amplio), estado físico o mental, o por circunstancias sociales, económicas, étnicas y/o culturales, migración y privación de libertad. En cuyos casos se requerirá informe de especialista acerca de la existencia de riesgos para la salud psicofísica de las víctimas o testigos, en virtud de su participación en el proceso penal hondureño.

En la atención a los grupos vulnerables frente al proceso como parte de las medidas Procesales se debe de propiciar medidas de simplificación y divulgación de los requisitos exigidos por el ordenamiento para la práctica de determinados actos, a fin de favorecer el acceso a la justicia de las personas en condición de vulnerabilidad, y sin perjuicio de la participación de otras instancias que

13 Publicado en el DIARIO OFICIAL LA GACETA. Acuerdo 01-2017. Art. 2. puedan coadyuvar en el ejercicio de acciones en defensa de los derechos de estas personas ${ }^{14}$. Es decir, el sistema se adapta a las necesidades de la víctima para su participación en el proceso y no, a la inversa.

\section{No revictimización durante el Juicio}

Excepcionalmente podrán ser incorporados al juicio por lectura o reproducción, bajo los supuestos siguientes del articulo $311 \mathrm{del}$ C.P.P., donde entre otros debemos rescatar el numeral 1, 2 y el 7, en razón de nuestro estudio: 1) Los testimonios o pericias que se hayan recibido antes del debate, conforme a las reglas de la prueba anticipada y que resulte imposible reproducir en el acto del juicio; 2) Los testimonios o pericias practicadas durante la etapa preparatoria, cuando sea imposible o extraordinariamente difícil su reproducción en el acto del juicio oral; 7) Los testimonios o diligencias relacionadas a las personas en estado de vulnerabilidad descritas en el Artículo 237-A de esta Código, obtenidas a través de medios audiovisuales o dispositivos análogos, siempre y cuando se hayan cumplido los requisitos establecidos en el Artículo 237B. ${ }^{15}$

La Corte Suprema de Justicia hondureña, ha considerado en varias ocasiones, que la imposibilidad material de comparecer al juicio para declarar nuevamente es equiparable e incluso se ve superada, por la condición de vulnerabilidad del sujeto. Pudiéndose

14. Regla $n^{\circ} 34,100$ Reglas de Brasilia para el Acceso a la Justicia

15 Artículo 311. Reformado por Adición numeral $7 \mathrm{y}$ derogación del párrafo segundo por Decreto 6-2017 de fecha 22 de febrero de 2017 y publicado en el Diario Oficial La Gaceta No.34,276 de fecha 27 de febrero de 2017. 
incorporar al proceso la sola reproducción de la declaración, siempre y cuando haya respetado las garantías del contradictorio, sin menos cabo del derecho de la víctima a estar enterada del proceso ${ }^{16}$. Por ejemplo, con el interés superior del niño, donde el mismo prevalece frente a otros derechos igualmente legítimos ${ }^{17}$. Tomando en consideración tres alcances esenciales: como derecho, principio interpretativo y norma procedimental.

\section{CONCLUSIÓN:}

- El ISN, no es un objeto normativo de protección. Así como el ejercicio del mismo, no se supedita de forma pasiva, a la aspiración del interés que el adulto quiera interpretar a favor del niño. El ISN es independiente y exige de todas las personas que intervienen en procesos de niñez, tanto en el ámbito público, privado, administrativo y legislativo, un análisis y un

16 Casación Penal (2014) Magistrado Rafel Bustillo (revisado en sistema de indexación http://jurisprudencia.poderjudicial. gob.hn/ConsultaHN/VerCas.aspx?reg=8072) CP. $275-14$,: Los testimonios o pericias que se hayan recibido antes del debate, conforme a las reglas de la prueba anticipada y que resulten imposible reproducir en el acto del juicio; por lo que en aplicación irrestricta de lo que establece dicha norma procesal, es obligación del Tribunal incorporar por lectura durante la audiencia de juicio oral, todos aquellos testimonios que se hayan recibido conforme a las reglas de la prueba anticipada,

17 Casación Penal CP. 275 -14: El principio del Interés Superior del Niño y Niña, también conocido como el interés superior del menor, es un conjunto de acciones y procesos tendientes a garantizar un desarrollo integral y una vida digna, así como las condiciones materiales y afectivas que permitan vivir plenamente y alcanzar el máximo de bienestar posible a niñas y niños. Se trata de una garantía de que las niñas y los niños tienen derecho a que, antes de tomar una medida respecto de ellos, se adopten aquellas que promuevan y protejan sus derechos y no las que los conculquen. Así, se tratan de superar dos posiciones extremas: el autoritarismo o abuso del poder que ocurre cuando se toman decisiones referidas a los niños y niñas, por un lado, y el paternalismo de las autoridades por otro. El interés superior del niño es un concepto triple; es un derecho, es un principio y es una norma de procedimiento. examen para garantizar el ejercicio efectivo de los derechos de la infancia, de forma amplia atendiendo el bienestar del niño, no como objeto de la política social u objeto de protección, sino como protagonista, un verdadero sujeto de derechos.

- Atender el Interés superior del niño, implica dejar de comprender los derechos del niño en un sentido negativo, con visión paternalistas. Exige de nosotros percibirlos en un sentido positivo, facilitarles el acceso a sus derechos en condiciones dignas, garantizarles sus derechos económicos,sociales y culturales, por sus derechos no se los podemos dar, sencillamente no se les pueden quitar, porque son inherentes a ellos.

\section{BIBLIOGRAFÍA}

Ávila Santamaría, R. F. (2012). Los derechos y sus garantías: ensayos críticos. Quito: Corte Constitucional para el Período de Transición.

Ballesté, I. R. (2012). El interés superior del niño: concepto y delimitación del término. Educatio siglo XXI, 30(2), 89-108.

Bruñol, M. C. (1999). El interés superior del niño en el marco de la Convención Internacional sobre los Derechos del Niño. Justicia y Derechos del Niño número, 125.

Corte Suprema de Justicia de Honduras (2014), Magistrado Ponente Rafael Bustillo (véase el sistema de indexación jurisprudencial 
de la Corte Suprema de Justicia http:// jurisprudencia.poderjudicial.gob.hn/ ConsultaHN/VerCas.aspx? reg=8072) Casación Penal, CP. 275 -14

CIDH (2002), Corte Interamericana de Derechos Humanos en la Opinión Consultiva OC 17/02 de la Condición Jurídica y Derechos Humanos del Niño, en resolución del 28 de agosto del 2002

CIDH (2015), Violencia, Niñez y Crimen Organizado, 11 de noviembre 2015.

Fanlo, I. (Ed.). (2004). Derechos de los niños: Una contribución teórica. Fontamara.

De Piñeres Botero, C. G., Coronel, E., \& Pérez, C. A. (2009). Revisión teórica del concepto de victimización secundaria. Liberabit. Revista de Psicología, 15(1), 49-58.

IBCR, (2017) "Informe del Mapeo del Sistema de Protección de la Niñez y Adolescencia en Honduras". (Revisado el 3 de junio 2019 http://www.ibcr.org/wp-content/ uploads/2018/06/Informe-del-Mapeo-delSistema-de-Proteccion-WEB.pdf)

Liebel, M. (2015). Sobre el interés superior de los niños y la evolución de las facultades. In Anales de la Cátedra Francisco Suárez (Vol. 49, pp. 43-61).

Mantilla, S. (2015) "La revictimización como causal del silencio de la víctima." Rev. Ciencias forenses Honduras 1.2 (2015): 3-12.
Pinto, M. (1997). El principio pro homine. Criterios de hermenéutica y pautas para la regulación de los derechos humanos. La aplicación de los tratados de derechos humanos por los tribunales locales, 163.

Talavera Elguera, P. (2009). La Prueba en el Nuevo Proceso Penal: Manual del Derecho Probatorio y de la valorización de las pruebas en el Proceso Penal Común. Lima.

Trijueque, D. G., Marina, S. D., \& López, E. G. (2010). Valoración pericial psicológica de la víctima de mobbing. Psicología Iberoamericana, 18(2), 8-18.

Zermatten, J. (2003). El Interes Superior del Niño: Del analisis literal al alcance filosofico (pp. 1-30). Institut international des droits de l'enfant: Institut universitaire Kurt Bösch. 